Proceedings of XIX International Scientific Conference "New Technologies and Achievements in Metallurgy, Material Engineering, Production Engineering and Physics", Częstochowa, Poland, June 7-8, 2018

\title{
Transmission in the Phononic Octagonal Lattice Made of an Amorphous Zr55Cu30Ni5Al10 Alloy
}

\author{
S. Garus*, M. Bold And W. Sochacki \\ Institute of Mechanics and Fundamentals of Machinery Design, Częstochowa University of Technology, \\ J.H. Dąbrowskiego 73, 42-201 Częstochowa, Poland
}

\begin{abstract}
Structures with aperiodic layering are characterized by extremely interesting phononic properties. There is a phononic band gap phenomenon in them, so the waves with given frequency ranges do not propagate in these structures. These properties allow the use of such structures as selective filters or devices for noise control. The study examined transmission of the quasi one-dimensional octagonal structure. The properties of the aperiodic structure were analyzed depending on the network's generation number and layers thickness. The transmission matrix algorithm was used for the analysis. The tested lattices were made of an amorphous $\mathrm{Zr}_{55} \mathrm{Cu}_{30} \mathrm{Ni}_{5} \mathrm{Al}_{10}$ alloy immersed in water. The influence of water temperature on transmission peaks shifts was also studied.
\end{abstract}

DOI: 10.12693/APhysPolA.135.139

PACS/topics: $61.44 . \mathrm{Br}, 43.58 . \mathrm{Kr}, 43.20 . \mathrm{Bi}, 43.20 . \mathrm{Gp}, 46.40 . \mathrm{Cd}$

\section{Introduction}

One of the characteristic properties of phononic structure is the presence of phononic band gaps (PhBG) [1]. Materials with aperiodic structure are used for construction of the selective acoustic filters, sensors, or noise suppressor $[2,3]$.

The transfer matrix method (TMM) [4], finite difference time domain (FDTD) $[5,6]$, plane wave expansion (PWE) [7] and finite element method (FEM) [8] are the most common in examination of phononic wave propagation properties. In this work the transfer matrix method algorithm is used.

Amorphous alloys are a widely studied group of materials in terms of their unique magnetic properties [9-13] as well as the magnetocaloric phenomena occurring in them [14-16]. In this work amorphous $\mathrm{Zr}_{55} \mathrm{Cu}_{30} \mathrm{Ni}_{5} \mathrm{Al}_{10}$ was used to build a quasi one-dimensional mechanical wave filter.

\section{Methods, materials and structure}

The TMM algorithm is characterized by high accuracy of the results obtained. It is a commonly used method for simulate the transmission spectra of quasi one-dimensional phononic crystals, quasicrystals and disordered structures. The TMM algorithm is used to analyze periodic [17] and aperiodic [18] multilayer structures.

\subsection{TMM algorithm}

In this paper, the TMM algorithm was used to determine the transmission in quasi one-dimensional octagonal

*corresponding author; e-mail: gari.sg@gmail.com structure. The relationship between the phase velocity $v_{i}$ and the pressure $p_{i}$ of the acoustic wave, which is propagating in a multilayer structure (where $i$ is layer number and $t$ is time) is defined as:

$$
\frac{1}{v_{i}^{2}} \frac{\partial^{2} p}{\partial t^{2}}-\nabla^{2} p=0 .
$$

Solution of Eq. (1), for the quasi one-dimensional multilattice structure, is given by

$$
p_{i}=\left(A_{i} \mathrm{e}^{\mathrm{i} k_{i} x}+B_{i} \mathrm{e}^{-\mathrm{i} k_{i} x}\right) \mathrm{e}^{-\mathrm{i} \omega t}=P_{i}(x) \mathrm{e}^{-\mathrm{i} \omega t},
$$

where $A_{i}$ is transmitted and $B_{i}$ - reflected wave coefficients for the frequency $f$. The wave vector $k_{i}$ is determined by

$$
k_{i}=2 \pi f / v_{i} .
$$

The acoustic impedance $Z_{i}$ in $i$-th layer is defined as:

$$
Z_{i}=v_{i} \rho_{i}
$$

where $\rho_{i}$ is $i$-th layer mass density. In multilayer structure the transition between the layers is described by matrix $\Phi_{i, i+1}$, which is expressed as

$$
\Phi_{i, i+1}=\frac{1}{2}\left[\begin{array}{ll}
\frac{Z_{i}+Z_{i+1}}{Z_{i}} & \frac{Z_{i+1}-Z_{i}}{Z_{i}} \\
\frac{Z_{i}-Z_{i+1}}{Z_{i}} & \frac{Z_{i}+Z_{i+1}}{Z_{i}}
\end{array}\right] .
$$

The propagation matrix $\Gamma_{i}$, corresponding to the $i$-layer with thickness $d_{i}$, can be written as

$$
\Gamma_{i}=\left[\begin{array}{cc}
\mathrm{e}^{\mathrm{i} k_{i} d_{i}} & 0 \\
0 & \mathrm{e}^{-\mathrm{i} k_{i} d_{i}}
\end{array}\right] .
$$

The propagation of the wave in a multilayer structure can be described by the matrix equation

$$
\left[\begin{array}{ll}
P_{\text {in }}^{+} & P_{\text {in }}^{-}
\end{array}\right]^{\mathrm{T}}=\mathrm{M}\left[\begin{array}{ll}
P_{\text {out }}^{+} & P_{\text {out }}^{-}
\end{array}\right]^{\mathrm{T}},
$$

where $P_{\text {in }}^{+}$is incident, $P_{\text {in }}^{-}$- reflected, $P_{\text {out }}^{+}-$transmitted wave and $P_{\text {out }}^{-}$is always 0 . M is characteristic matrix depending on the layers structure.

The simplest case of the propagation for one-layer structure is defined by Eq. (8): 


$$
\left[\begin{array}{ll}
P_{\text {in }}^{+} & P_{\text {in }}^{-}
\end{array}\right]^{\mathrm{T}}=\Phi_{\text {in }, 1} \Gamma_{1} \Phi_{1, \text { out }}\left[\begin{array}{ll}
P_{\text {out }}^{+} & P_{\text {out }}^{-}
\end{array}\right]^{\mathrm{T}} .
$$

The characteristic matrix $\mathrm{M}$ for $n$-elements multilayer structure takes the form

$$
\mathrm{M}=\Phi_{\mathrm{in}, 1}\left[\prod_{i=2}^{n} \Phi_{i-1, i} \Gamma_{i}\right] \Phi_{n, \text { out }} .
$$

The transmission coefficient $T$ of the multilayer aperiodic structure was determined from the characteristic matrix $\mathrm{M}$ and denoted as

$$
T=\left|\frac{1}{\mathrm{M}_{1,1}}\right|^{2} \text {. }
$$

\subsection{Analyzed structure}

Concatenation rule for quasi one-dimensional octagonal structure $\mathrm{X}_{L}[19]$ is given by

$$
\mathrm{X}_{L+1}=\mathrm{X}_{L} \mathrm{X}_{L} \mathrm{X}_{L-1} \text {, }
$$

where the initial conditions are

$$
\mathrm{X}_{0}=\mathrm{A}, \mathrm{X}_{1}=\mathrm{AB} \text {. }
$$

In Table I the distribution of layers in quasi periodic octagonal structures for generation numbers $L$ from 2 to 4 are presented. The letter A from Table I represents the layer made of amorphous alloy $\mathrm{Zr}_{55} \mathrm{Cu}_{30} \mathrm{Ni}_{5} \mathrm{Al}_{10}$, while $\mathrm{B}$ means the layer made of distilled water, in which the speed of sound propagation $v$ depends on the temperature $T$ and is determined by the following dependence $[20,21]$ :

$$
\begin{aligned}
& v(T)=1.40238744 \times 10^{3}+5.03836171 T \\
& -5.81172916 \times 10^{-2} T^{2}+3.34638117 \times 10^{-4} T^{3} \\
& -1.48259672 \times 10^{-6} T^{4}+3.16585020 \times 10^{-9} T^{5} .
\end{aligned}
$$

A significant change in the speed of mechanical waves depending on the temperature (Fig. 1) affects the shifts of the transmission peaks of the analyzed structures.

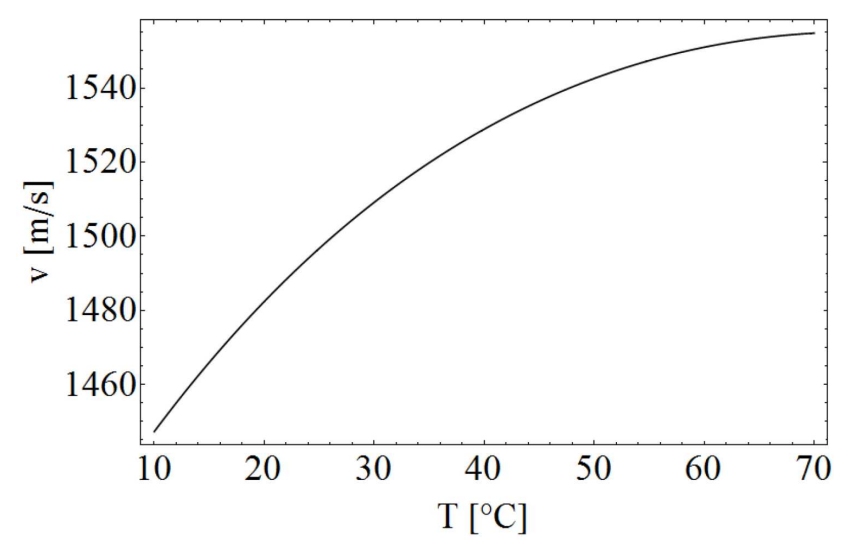

Fig. 1. Influence of temperature on the speed of mechanical waves in distilled water.

Table II shows the characteristics of the materials used. The material of the surroundings of the multilayer structure has always been distilled water at $20^{\circ} \mathrm{C}$.
Arrangement of the layers of analyzed structures.

\begin{tabular}{l|l}
\hline \hline $\mathrm{L}$ & $\mathrm{X}_{L}$ \\
\hline 2 & ABABA \\
3 & ABABAABABAAB \\
4 & ABABAABABAABABABAABABAABABABA
\end{tabular}

TABLE II

Material parameters of the components of the multilayer structure [20-22].

\begin{tabular}{l|c|c|c}
\hline \hline \multirow{1}{*}{ Material } & $\begin{array}{c}\text { Mass } \\
\text { density } \\
\rho\left[\mathrm{kg} / \mathrm{m}^{3}\right]\end{array}$ & $\begin{array}{c}\text { Velocity } \\
\text { of sound } \\
v[\mathrm{~m} / \mathrm{s}]\end{array}$ & $\begin{array}{c}\text { Layer } \\
\text { thickness } \\
d[\mu \mathrm{m}]\end{array}$ \\
\hline $\mathrm{Zr}_{55} \mathrm{Cu}_{30} \mathrm{Ni}_{5} \mathrm{Al}_{10}$ & 6829 & 1633 & 408.25 \\
distilled water & 998 & $1482\left(20^{\circ} \mathrm{C}\right)$ & 494.119
\end{tabular}

\section{Research}

The study investigated the transmission (Fig. 2) of a quasi-periodic octagonal superlattice with a structure of layers determined by the concatenation rule (11). There can be noticed the presence of two band gaps with a large frequency range. The half-width of the transmission peaks decreases as the number of layers increases. Peaks with high transmission are visible.

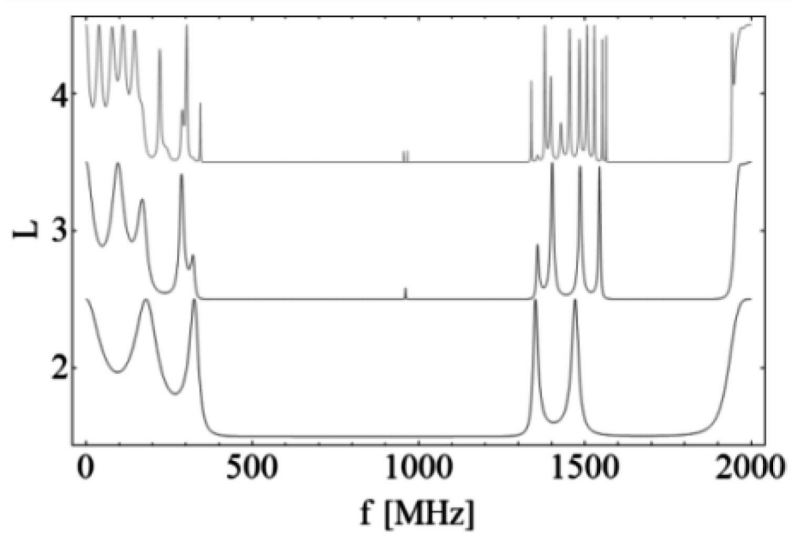

Fig. 2. Transmission of octagonal structures for three generations numbers $L=\{2,3,4\}$.

Figure 3 shows the shifts of the transmission peaks depending on the temperature of distilled water inside the structure for $L=3$. White color means full transmission through the structure, while black color means no transmission. It is clearly visible that the transmission peaks shift toward higher frequencies as the temperature increases.

Figure 3 shows the shifts of the transmission peaks depending on the temperature of distilled water inside the structure for $L=3$. White color means full transmission through the structure, while black color means no transmission. It is clearly visible that the transmission peaks shift toward higher frequencies as the temperature increases. 


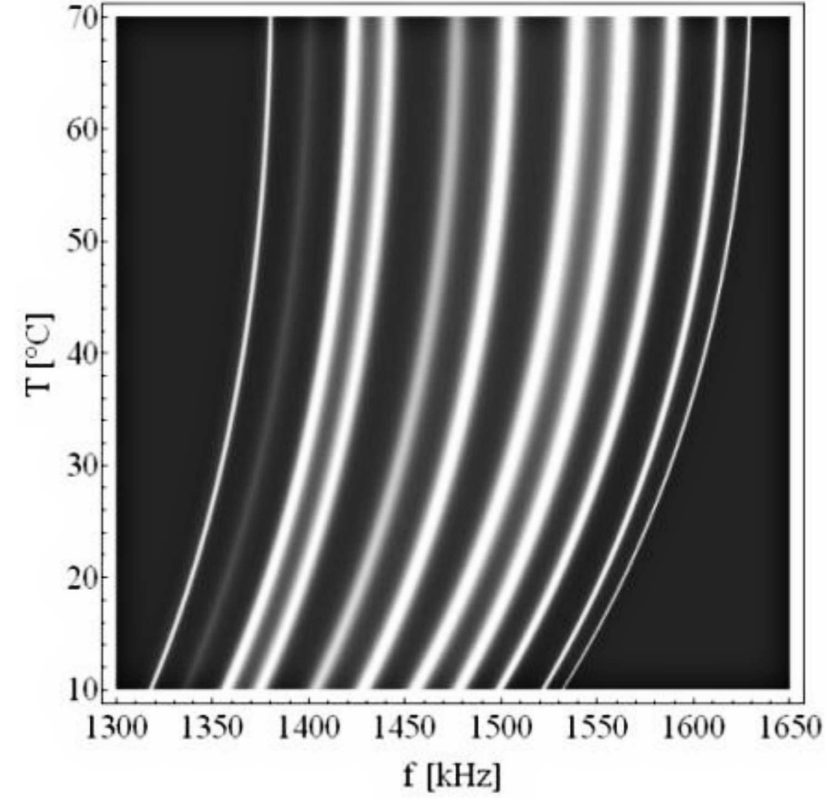

Fig. 3. Influence of the temperature of distilled water inside the structure on shifts of transmission peaks for $L=3$.
Figure 4 shows the effect of changing the thickness of the layer of materials included in the multilayer structure on the transmission of a mechanical wave. In Fig. $4 \mathrm{a}-\mathrm{c}$, the layer of material $\mathrm{Zr}_{55} \mathrm{Cu}_{30} \mathrm{Ni}_{5} \mathrm{Al}_{10}$ changed its thickness from 0.5 to 1.5 times the base value from Table II, respectively for $L$ equal to 2,3 , and 4 . The influence of the change in the thickness of the distilled water layer in Fig. 4d-f was analyzed analogously.

\section{Conclusions}

The conducted research revealed the occurrence of phononic band-gap for the range of ultrasonic mechanical waves in the octagonal structure made of amorphous alloy and distilled water.

The influence of the distilled water temperature on the transmission and the type of network structure (peaks of small half-width) allows the construction of flow temperature sensors based on aperiodic superlattices.

Changing the thickness of the layer causes non-linear shifts in the transmission peaks. (a)

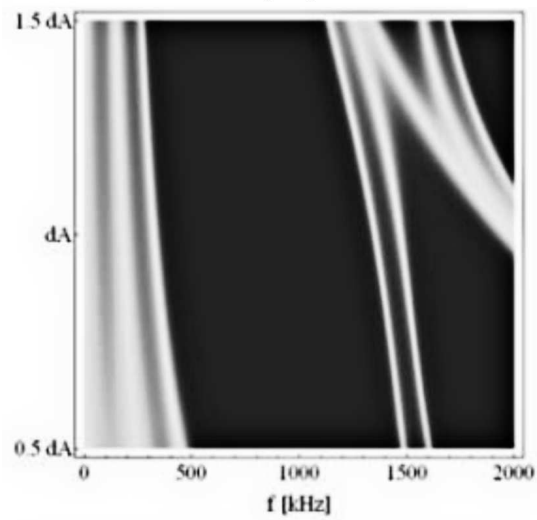

(d)

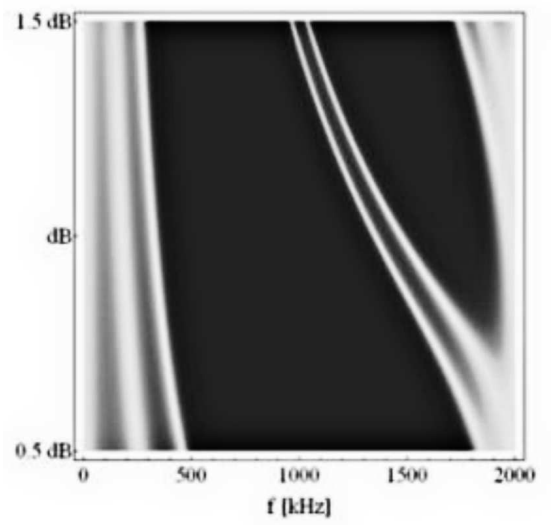

(b)

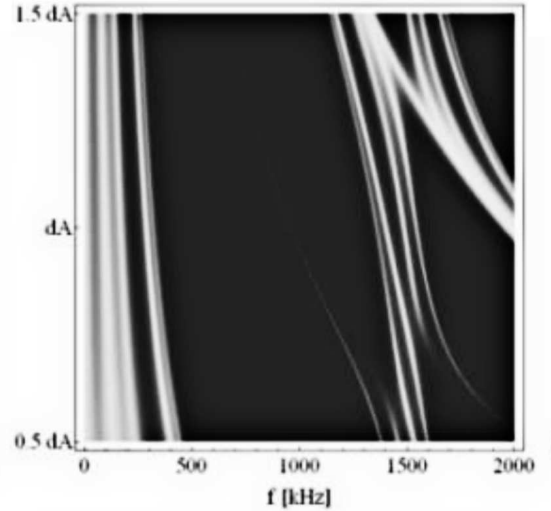

(e)

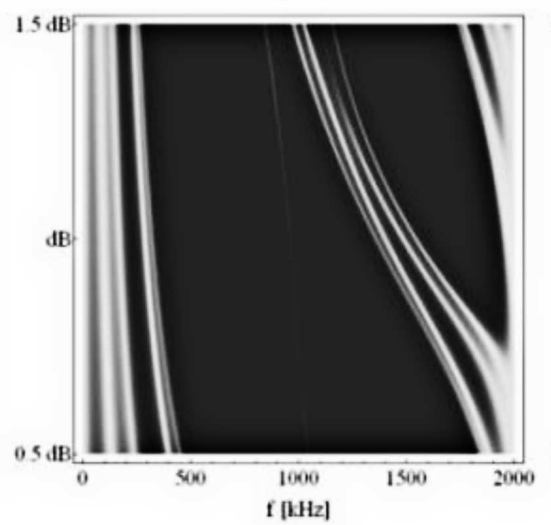

(c)

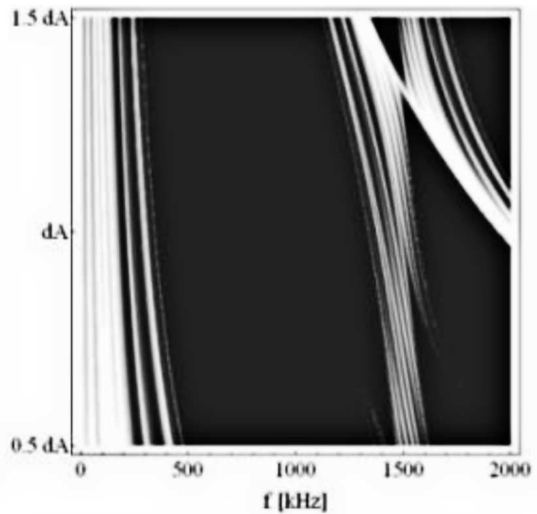

(f)

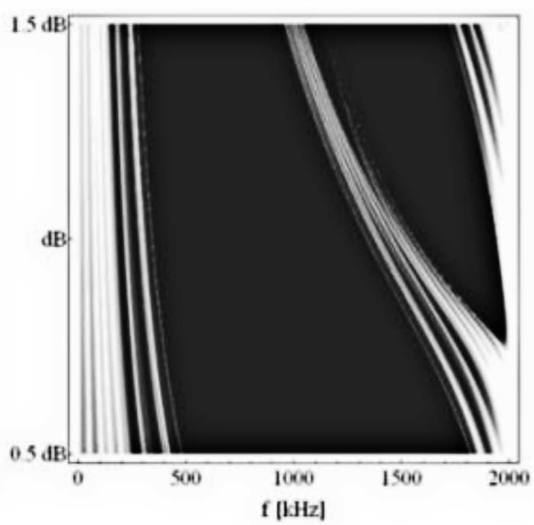

Fig. 4. Transmission for the octagonal structure in the range of the thickness of the amorphous alloy $d \mathrm{~A}$ from $0.5 d \mathrm{~A}$ to $1.5 \mathrm{~d}$ A for (a) $L=2$, (b) $L=3$, (c) $L=4$ and in the range of the thickness of the distilled water dB from $0.5 d$ A to $1.5 d$ A for (a) $L=2$, (b) $L=3$, (c) $L=4$. 


\section{References}

[1] K. Gruszka, M. Nabiałek, M. Szota, Adv. Mater. Sci. Eng. 68, 24 (2014).

[2] I. Kriegel, F. Scotognella, Physica E 85, 34 (2017).

[3] S. Villa-Arango, R. Torres, P.A. Kyriacou, R. Lucklum, Measurement 102, 20 (2017).

[4] M.N. Armenise, C.E. Campanella, C. Ciminelli, F. Dell'Olio, V.M.N. Passaro, Phys. Proced. 3, 357 (2010).

[5] A. Taflove, Computational Electrodynamics: The Finite-Difference Time-Domain Method, Artech House, Norwood (MA) 1995

[6] D.M. Sullivan, Electromagnetic Simulation Using the FDTD Method, IEEE Press, New York 2000.

[7] S.G. Johnson, J.D. Joannopoulos, Opt. Expr. 8, 173 (2001).

[8] D.L. Dwoyer, M.Y. Hussaini, R.G. Voigt, Finite Elements - Theory and Application, Springer-Verlag, New York 1986.

[9] M.G. Nabialek, P. Pietrusiewicz, M.J. Dospial, M. Szota, K. Błoch, K. Gruszka, K. Oźga, S. Garus, J. Alloys Comp. 615, S51 (2015).

[10] K. Błoch, M. Nabiałek, Acta Phys. Pol. A 127, 413 (2015).
[11] S. Garus, M. Nabiałek, J. Garus, Acta Phys. Pol. A 126, 960 (2014).

[12] J. Garus, S. Garus, M. Nabiałek, M. Szota, Acta Phys. Pol. A 126, 954 (2014)

[13] S. Garus, W. Sochacki, J. Appl. Math. Comput. Mech. 16, 17 (2017).

[14] P. Gebara, P. Pawlik, B. Michalski, J.J. Wysłocki, Acta Phys. Pol. A 127, 576 (2015).

[15] P. Gębara, P. Pawlik, J. Magn. Magn. Mater 442 , 145 (2017).

[16] P. Gebara, P. Pawlik, I. Skorvanek, J. Marcin, J.J. Wysłocki, Acta Phys. Pol. A 118, 910 (2010).

[17] M.M. Sigalas, C.M. Soukoulis, Phys. Rev. B 51, 2780 (1995).

[18] S. Garus, W. Sochacki, J. Appl. Math. Comput. Mech. 16, 17 (2017).

[19] J.E.S. Socolar, Phys. Rev. B 39, 10519 (1989).

[20] N. Bilaniuk, G.S.K. Wong, J. Acoust. Soc. Am. 93 , 1609 (1993)

[21] N. Bilaniuk, G.S.K. Wong, J. Acoust. Soc. Am. 99 , 3257 (1996)

[22] M. Fukuhara, X. Wang, A. Inoue, J. Non-Cryst. Solids 356, 1707 (2010). 